\title{
Evaluation of Stormwater System Influence on the River Using Algae
}

\section{Roman Babko', Joanna Szulżyk-Cieplak ${ }^{2 *}$, Yaroslav Danko, Sylwia Duda ${ }^{4}$, Marina Kirichenko-Babko', Grzegorz Łagód ${ }^{5}$}

\author{
1 Schmalhausen Institute of Zoology NAS of Ukraine, B. Khmelnitsky Str. 15, Kyiv, 01030, Ukraine \\ 2 Lublin University of Technology, Faculty of Fundamentals of Technology, Nadbystrzycka 38, 20-618 Lublin, \\ Poland \\ 3 Sumy Makarenko State Pedagogical University, Romenska, 87, 40002 Sumy, Ukraine \\ 4 Institute of Rural Health in Lublin, Department of Woman Health, Jaczewskiego 2, 20-090 Lublin, Poland \\ 5 Lublin University of Technology, Faculty of Environmental Engineering, Nadbystrzycka 40B, 20-618 Lublin, \\ Poland \\ * Corresponding author's e-mail: j.szulzyk-cieplak@pollub.pl
}

\begin{abstract}
One of the widespread sources of river pollution is the wastewater coming from both wastewater treatment plants and the stormwater system. Wastewater can vary significantly in composition and concentration of substances introduced into water bodies. Municipal effluents may contain significant amounts of organic matter and ammonia. Storm drains are diverse in composition and depend on the nature of the surface from which the water collects, but carry more suspended solids and less nutrients. The research was aimed at assessing the effect of surface runoff collected by the stormwater system from the territory of the city of Lublin on the Bystrica River using popular environmental indices, calculated on the basis of periphytonic algae species abundances: species number, Shannon's H, rarefied species number, Pielou's evenness, trophic diatom index (TDI). It was observed that the correspondence between a species diversity and the quality of the environment is not always straightforward. Therefore, the periphytonic algae diversity increases under the influence of runoff, as evidenced by the Shannon index. Nevertheless, pronounced changes are noted in the structure of the algal community, as shown by the Pielou index and NMDS. However, these changes in the structure are invisible if the trophic diatom index (TDI) is relied upon.
\end{abstract}

Keywords: stormwater system, river, water quality, bioindication, algae environmental indices

\section{INTRODUCTION}

The intact natural hydroecosystems of the flatland rivers of Europe, in the absence of the anthropic influence, correspond mainly to the oligosaprobic conditions [Grizzetti et al., 2017]. At the same time, a high diversity of hydrobiocenoses was the result of the complex trophic networks formed during evolution, the existence of which was predetermined by a diverseness of conditions. Most modern rivers experience, in varying degree, various forms of new for nature influences [Acreman et al., 2004; Poff et al., 2007; Poff, Zimmerman, 2010; Vörösmarty et al., 2010]. One of the widespread sources of river pollution is the wastewater coming from both wastewater treatment plants and the stormwater system [Gücker et al., 2006; Spänhoff et al., 2007; Babko et al. 2016, 2019; Pliashechnyk et al., 2018]. Wastewater can vary significantly in composition and concentration of the substances introduced into water bodies. Municipal effluents may contain significant amounts of organic matter and ammonia [Strom et al., 1976] Storm drains are diverse in composition and depend on the nature of the surface from which the water collects, but carry more suspended solids and less nutrients [Calmano et al., 1993; Eriksson et al., 2007; Helmreich et al., 2010; Grung et al., 2016; Ma et al., 2018]. 
The decomposition of organic matter in water bodies leads to a significant decrease in the oxygen content in water [Courchaine, 1968]. Under the influence of wastewater, the composition of the bottom sediments changes, and the concentration of organic carbon, nitrogen, and phosphorus increases [Gücker et al., 2006]. The effects of effluents can spread downstream for $1 \mathrm{~km}$ or more [Wakelin et al., 2008]. Downstream of the wastewater discharge, the conditions change, leading to a restructuring of the communities of both autotrophs and heterotrophs. According to Madoni, under the influence of the discharges of the untreated effluents in the Parma River (northern Italy), the composition of bottom communities became monotyped over a ten-year period. Under the influence of wastewaters in the areas below the confluence of drains, there was an increase in the similarity of the species composition of hydrobionts between the mountain and lowland rivers, and the similarity between the flatland sections of the river increased more noticeably [Madoni, 1993]. Under the influence of runoffs and increased organic load, the trophic structure of the ciliate assemblage changes, the proportion of algophages decreases and the proportion of bacteriophages increases [Madoni \& Zangrossi, 2005]. In the flatland flowing waters, under the influence of wastewater, there is an increase in the biomass of macrophytes and bottom invertebrates, increased respiration of the entire community and an increase in gross primary production, which can be explained by the receipt of an energy subsidy from wastewater [Gücker et al., 2006].

A study on the colonization of artificial substrates by algae and invertebrates in the river section under the influence of wastewater showed that the composition of the periphytonic algae was changed compared to the sites above the zone of influence. Many species that were present in the river section upstream of the discharge site were not observed in the section located downstream [Lewis, 1986].

However, the balance between the diversity of organisms and the quality of the environment is sometimes ambiguous. The pollution of the environment, especially with organic substances, does not necessarily lead to a decrease in the diversity of the autotrophic and heterotrophic components of ecosystems [Correa et al., 2015]. Therefore, the notion of water quality does not always coincide with such important parameters as species diversity (number of species) and biodiversity, e.g. under the $\beta$-mesosaprobic conditions, the diversity can significantly increase along with the resource base [Sun et al., 2019].

The natural flowing waters affected by effluents often have a depleted community composition of invertebrate organisms even upstream of the wastewater inflows, as they are exposed to other factors causing eutrophication and community degradation [Gücker et al., 2006]. The powerful factors leading to the monotyping of environmental conditions in rivers are artificial deepening and straightening of channels, regulation of the hydrological regime by locks and dams, and the load on hydroecosystems by the inflow of pollutants from dispersed sources [Ward et al., 1999; Sweeney et al., 2004; Belletti et al., 2015]. In such rivers, bottom sediments of the same type are observed, in addition to the absence of reaches and sills, a relatively uniform flow throughout the entire length of the transformed sections of the channel. Paradoxically, in such rivers, the increase of diversity into the river may be caused by runoffs, especially if the runoffs do not contain toxic substances that lead to the death of the aquatic organisms.

The conducted studies aimed at assessing the effect of the surface runoff collected by the stormwater system from the city of Lublin on the Bystrica River using popular environmental indices. The authors attempted to evaluate the local influence of runoff on the diversity of algae in a river, the anthropic transformations of which led to a high degree of monotyping of the conditions in the river channel, which was straightened, deepened, and deprived of the connections with floodplain water bodies due to the dams along both banks.

\section{MATERIALS AND METHODS}

The research was carried out on the segment of the Bystrica river localized within the city of Lublin (Poland). The algae samples were collected at the confluence of the stormwater inflow and Bystrica and at a distance of $50 \mathrm{~m}$ before and beyond of it. Description of the segment of Bystrica in the study area was given in a previous publication [Babko et al., 2019]. The samples of algae were scraped from a fixed surface area of $1 \mathrm{~cm}^{2}$ to $5 \mathrm{~cm}^{2}$. The algae living space was considered as the volume of water below the surface of height of $0.5 \mathrm{~cm}$. In the laboratory, before each abundance 
calculation, the sample was homogenized in a centrifuge at low speed. Subsamples of $25 \mathrm{mkl}$ were processed. Depending on the abundances of the counted objects from 7 to 11 , the subsamples were analyzed. The averaged data were presented as abundances per $1 \mathrm{~cm}^{3}$. These calculations allowed obtaining comparable quantitative results on every station regardless of the actual area of the samples taken. On the basis of the abundances of algae population and diversity of their species, a number of generally accepted in ecology indices was calculated. The samples were treated in the laboratory of the Lublin University of Technology immediately after selection. The following indices were used to assess the level of diversity in each of the research stations: species number, Shannon's H, rarefied species number, Pielou's evenness, trophic diatom index (TDI). The TDI, an index designed for monitoring the trophic status of rivers based on diatom composition [Kelly, Whitton 1995, Kelly 1996]:

$$
T D I=\frac{\sum_{j=i}^{n} a_{j} v_{j} i_{j}}{\sum_{j=i}^{n} a_{j} v_{j}}
$$

where: $a_{j}-$ abundance (proportion) of species $\mathrm{j}$ in sample, $v_{j}$ - indicator value (1-3) and

$i_{j}$ - pollution sensitivity $(1-5)$ of species $\mathrm{j}$. The value of TDI can range from 1 (very low nutrient concentrations) to 5 (very high nutrient concentrations).

The data on the abundances of species were processed using R Version 3.6.0 [R Core Team, 2019]. Shannon's H was calculated using function diversity, rarefied species numbers - rarefy form the vegan package [Oksanen et al. 2019]. Nonmetirc Multidimensional Scaling was performed using metaMDS from vegan package. In order to assess the significance of pairwise differences between the stations, $t$ analysis of variance (ANOVA) and post-hoc Tukey HSD (Honestly Significant Difference) test were performed with aov and TukeyHSD functions, respectively in the $\mathrm{R}$ package stats. Plots were produced with the R package ggplot2 [Wickham, 2009].

\section{RESULTS AND DISCUSSION}

According to the data obtained, in the effluent and upstream of confluence, the number of species was fairly close, while downstream, a considerable tendency to increase in this value emerges (Fig 1). Even more clearly, the trend can be seen in Figure 1B, which shows the rarefied data on the species numbers. With high probability, the increase in the number of species at the third station is the result of the impact of stormwater system. Downstream of discharge, the conditions in the river change in the direction of increasing in the number of niches available, and the populations developed in the drain appear. This situation confirms that at low levels of allochthonous organics, the species diversity may increase.

It was previously shown [Babko et al., 2019] that despite the small volume and irregularity of the surface runoff volume into the Bystrica river in the study area, the structure of algae assemblages in periphyton significantly differed both in the qualitative composition and in the quantitative development of populations.

The assessment of the differences in the algae diversity at the studied sites on the basis of the Shannon index showed that the species diversity increases, as does the number of species below the runoff from the stormwater system (Fig. 2 A). At the same time, in station 3, an increase in the Pielou's evenness index is also observed (Fig. 2B).

The increase in the Pielou's index is consistent with the saprobity index considered in [Babko et al. 2019]. In fact, an increase in evenness indicates the stabilization of the structure of the algal assemblage with an increase in the trophic level in the river downstream of the stormwater discharge inflow.

Thus, against the background of increasing diversity and the number of species at the station below the runoff, the conditions contribute to the stabilization of the structure of algal assemblages. An increase in the evenness values due to an increase in the abundances of species with particular environmental requirements is a good indicator of the stabilization of conditions.

The conclusion regarding the moderate influence of the stormwater system can be confirmed by the fairly authoritative diatom index (TDI). The so-called Trophic Diatom Index (TDI) was developed on the basis of the concept of species differentiation and intensive field research by Schiefele and Kohmann [Schiefele and Kohmann, 1993]. This index characterizes the trophic level of streams and rivers using seven levels similar to the saprobic system. However, both those classifications are independent and their 
a)

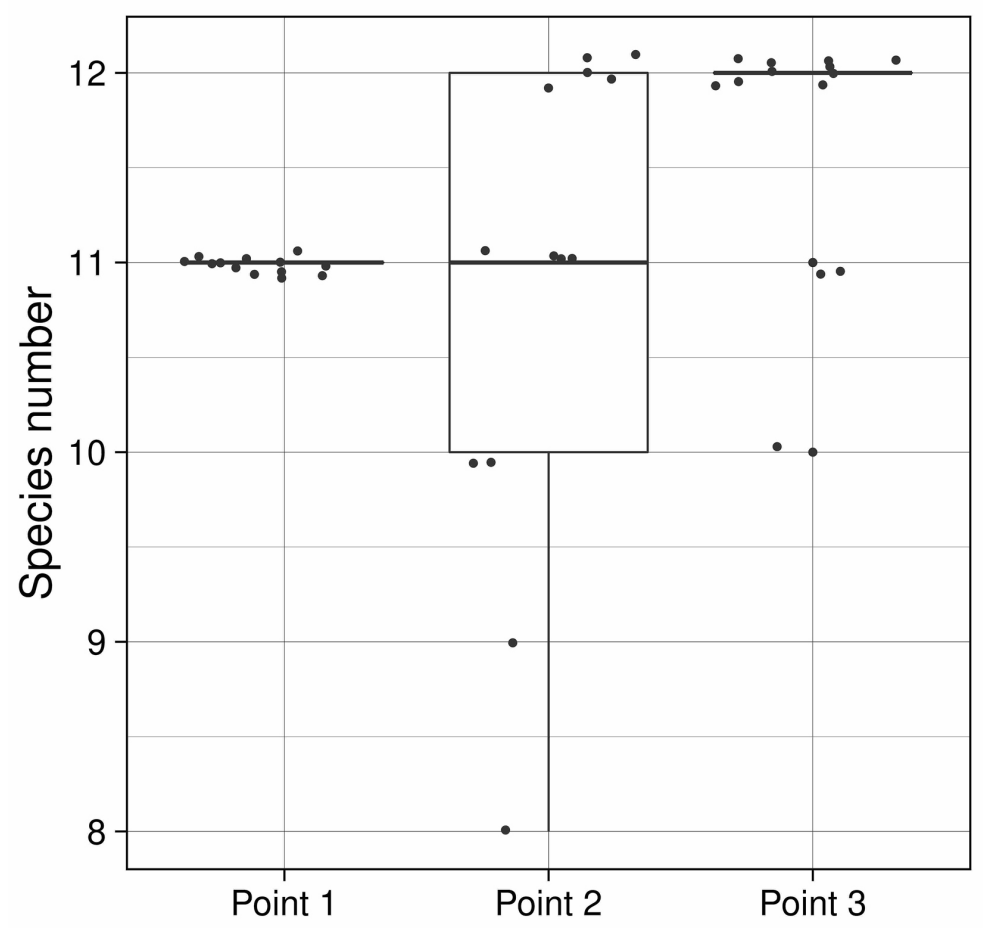

b)

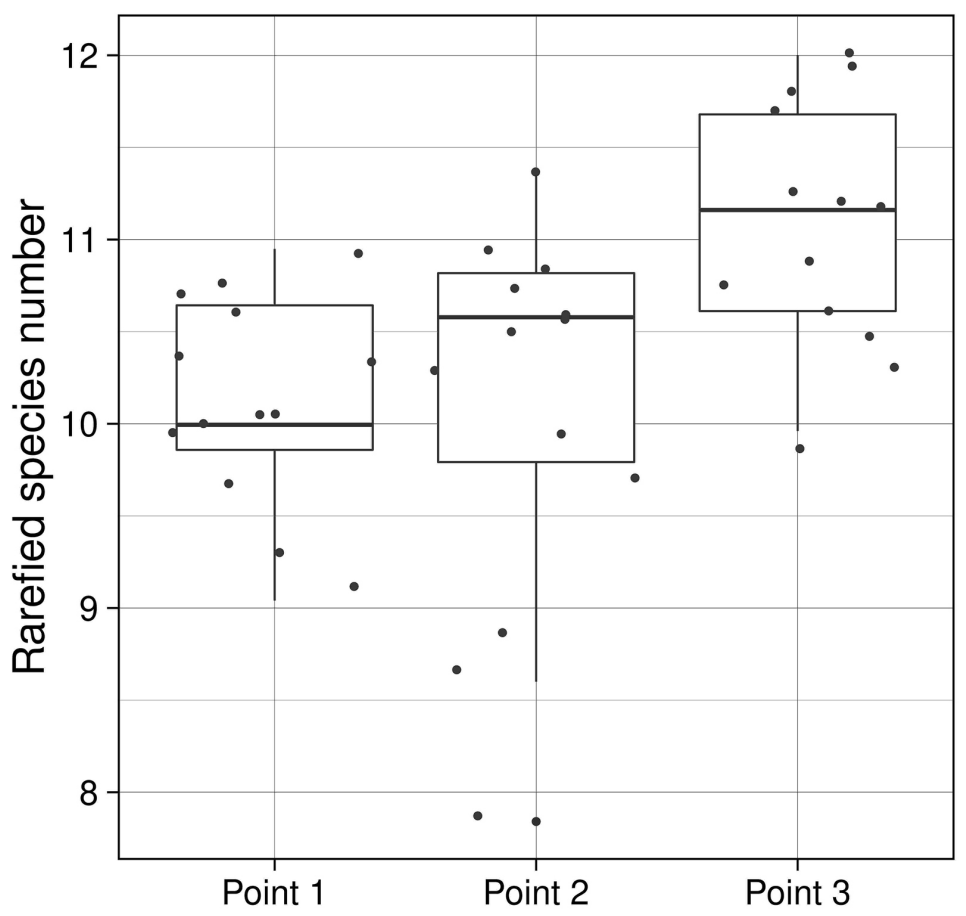

Figure 1. (A) Species number and (B) rarefied species number at the studied sampling points

levels are unequal. The value of TDI lies in its ability to better reflect the changes in the trophic level than other saprobic indices [Dokulil, 2003]. TDI is best used for neutral or slightly alkaline, meso- and hypertrophic waters. In our case, it is most appropriate, as it is designed for rivers and works optimally in the range of mesosaprobic conditions.
In our case, the TDI value indicates the absence of a considerable effect of wastewater from stormwater on parts of the river under its influence. This index is much more appropriate here in contrast to the saprobity index. It should be noted that the ratio of the TDI index values is closest to the ratio of the density of algae 
a)

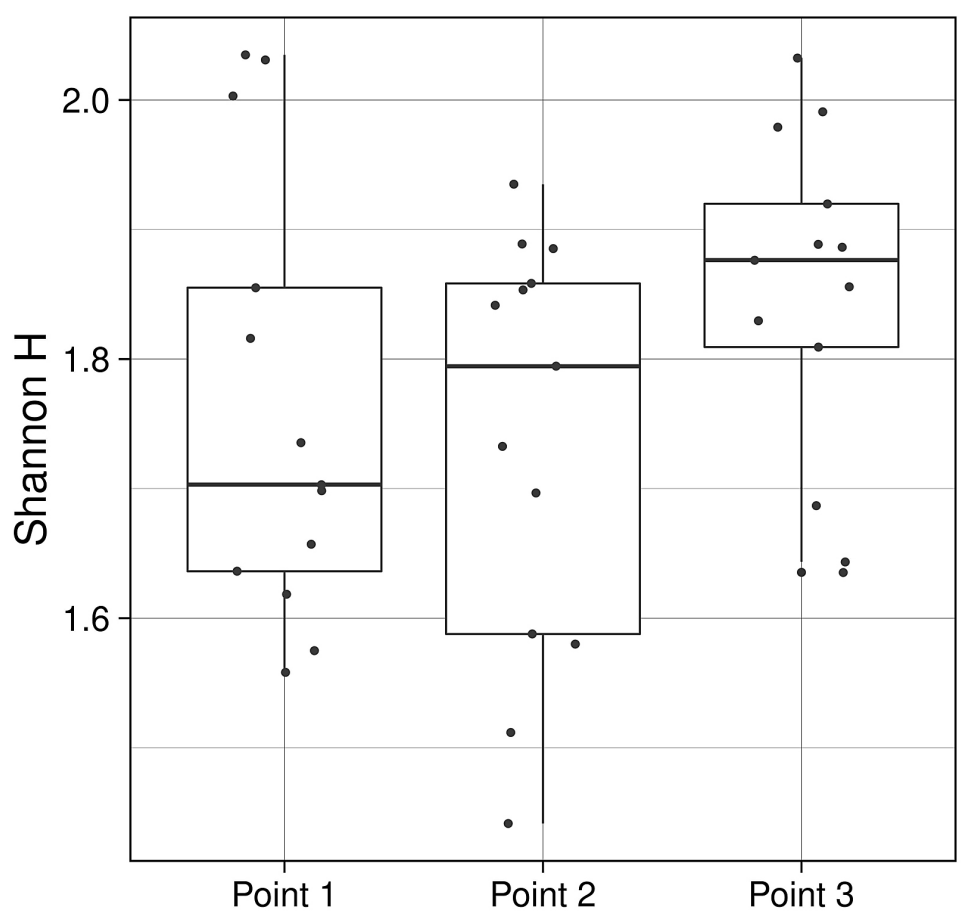

b)

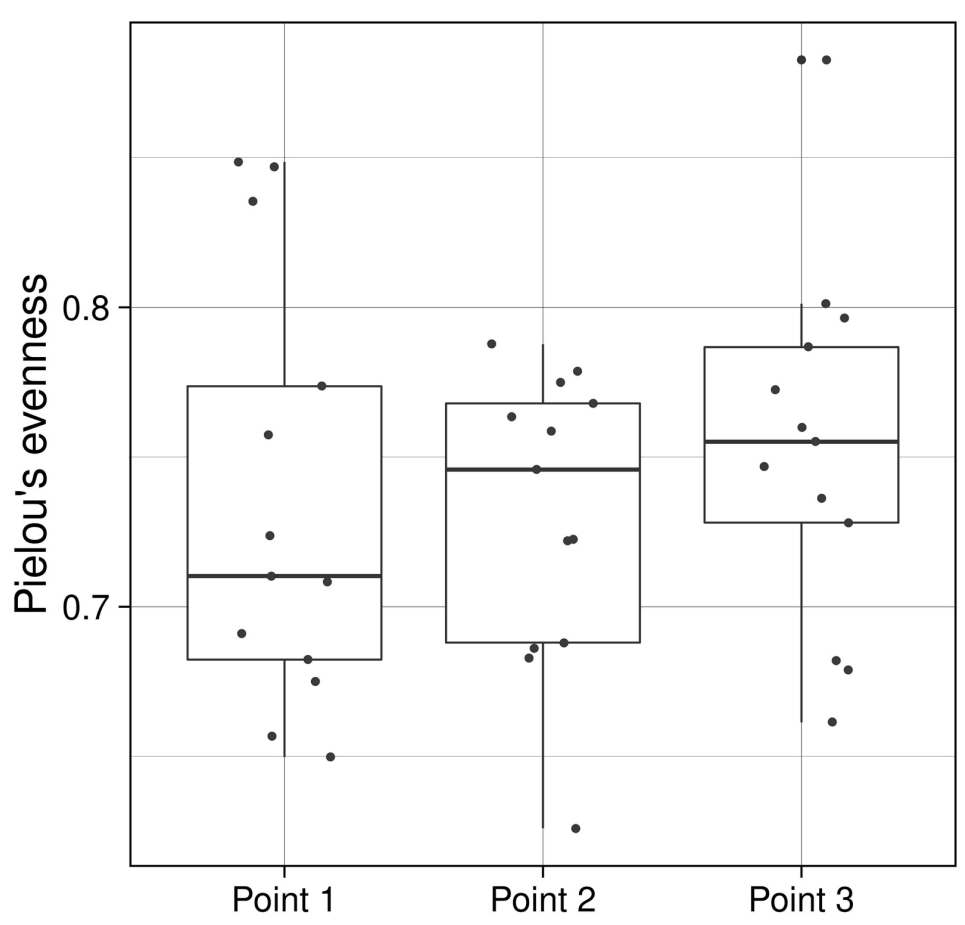

Figure 2. Alpha-diversity indices values: (A) Shannon's H and (B) Pielou's evenness at the studied sampling points

populations - indicators of the $\beta$-mesosaprobic conditions [Babko et al., 2019].

From the graph in Fig. 3A one can make a conclusion that either the index is not sensitive enough, or the wastewater from stormwater does not significantly affect the situation in the river below the runoff. The NMDS method was used to analyze the degree of structural rearrangements in algal assemblages at the studied stations. As can be seen in Fig. 3B, the assemblages at the three stations, although close, demonstrate a significant individuality level, which confirms the thesis that the influence of the runoff from stormwater does not change the trophic status in the studied area, but it has a significant effect on the composition and quantitative development of algae (Fig. 3B). 


\section{CONCLUSION}

Regarding the influence of the stormwater system on periphytonic algae, it can be argued that their diversity increases under the influence of runoff, as evidenced by a change in the Shannon index. An increase in the diversity of algae is accompanied by an increase in the evenness of the structure of their assemblage, which is recorded by the Pielou's index.
In general, as shown earlier, the effect of runoff manifests itself in an increase in the saprobity index [Babko et al., 2019], while the TDI index remained stable at all stations. The ranges in which the indices of saprobity and TDI change indicate that the runoff from the stormwater system does not change the trophic status of the river, and in the studied area, the water quality corresponds to the $\beta$-mesosaprobic conditions. A marked increase in the diversity of algae according to the

a)

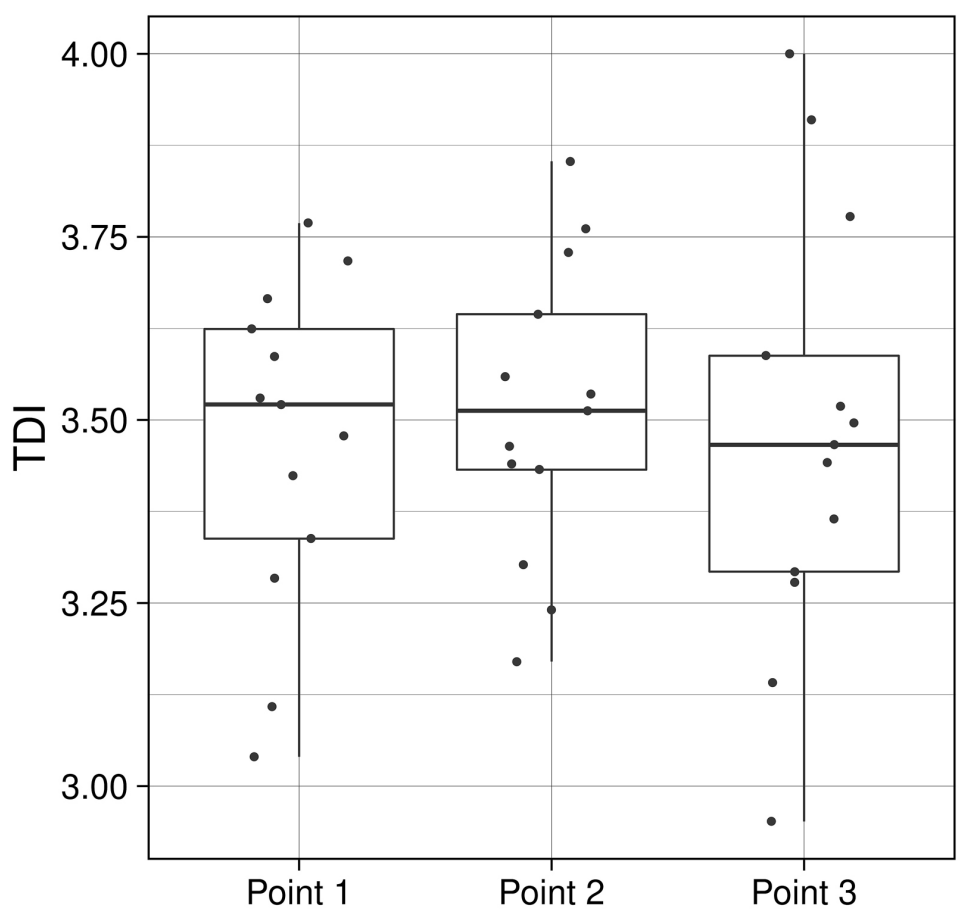

b)

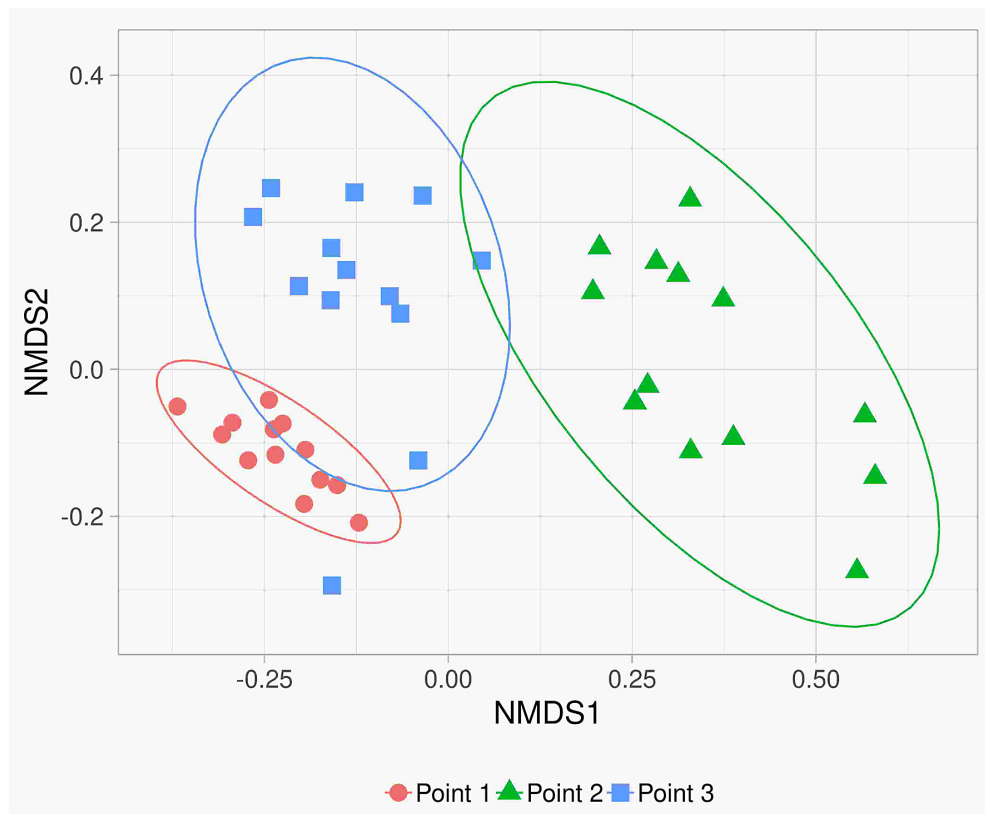

Figure 3. Values of trophic diatom index (TDI) at the studied sampling points. (B) NMDS of the samples taken based on the matrix of species abundances 
Shannon's index indicates that the wastewater from the stormwater system significantly alter the structure of algae assemblages, without changing the trophic level of water in a noticeable way.

It is probably important to note that the indices used have different sensitivity, and it is important to continue the search for new approaches to assessing both the quality of the aquatic environment and the response of the biological component of water bodies.

\section{REFERENCES}

1. Acreman M., Dunbar M.J. 2004. Defining environmental river flow requirements - A review. Hydrology and Earth System Sciences, 8, 861-876.

2. Babko R., Kuzmina T., Suchorab Z., Widomski M.K., Franus M. 2016. Influence of treated sewage discharge on the benthos ciliate assembly in the lowland river. Ecological Chemistry and Engineering S, 23(3), 461-471.

3. Babko R., Szulżyk-Cieplak J., Danko Y., Duda S., Kirichenko-Babko M., Łagód G. 2019. Effect of stormwater system on the receiver. Journal of Ecological Engineering, 20(6), 52-59. doi. org/10.12911/22998993/109433.

4. Belletti B., Rinaldi M., Buijse A.D., Gurnell A.M., Mosselman E. 2015.A review of assessment methods for river hydromorphology. Environmental Earth Sciences, 73, 2079-2100.

5. Calmano W., Hong J., Förstner U. 1993. Binding and Mobilization of Heavy Metals in Contaminated Sediments Affected by $\mathrm{pH}$ and Redox Potential. Water Science and Technology, 28, 223-235.

6. Corrêa L.V.A., Hardoim E.L., Zeilhofer P. 2015. Is the periphytic structure of Testaceans (Protozoa: Rhizopoda) related to water quality: a case study in the Cuiabá River, Brazil. Applied Ecology and Environmental Research, 13(1), 85-97.

7. Courchaine R. J. 1968. Significance of nitrification in stream analysis: effects on the oxygen balance. J. Water Pollut. Control Fed., 40, 835-847.

8. Dokulil M.T. 2003. Chapter 9: Algae as ecological bio-indicators. In Bioindicators and biomonitors. Ed. B.A. Markert, A.M. Breure, H.G. Zechmeister, 285-327.

9. Eriksson E., Baun A., Scholes L., Ledin A., Ahlman S., Revitt M., Noutsopoulos C., Mikkelsen P.S. 2007. Selected stormwater priority pollutants - a European perspective. Science of The Total Environment, 383, 41-51.

10. Grizzetti B., Pistocchi A., Liquete C., Udias A., Bouraoui F., van de Bund W. 2017. Human pressures and ecological status of European rivers. Sci Rep, 7, 205. doi:10.1038/s41598-017-00324-3.
11. Grung M., Petersen K., Field E., Allan I., Christensen J.H., Malmqvist L.M.V., Meland S., Ranneklev S. 2016. PAH related effects on fish in sedimentation ponds for road runoff and potential transfer of PAHs from sediment to biota. Science of The Total Environment, 566-567, 1309-1317.

12. Gücker B., Brauns M., Pusch M. T. 2006. Effects of wastewater treatment plant discharge on ecosystem structure and function of lowland streams. J. N. Am. Benthol. Soc., 25, 313-329.

13. Helmreich B., Hilliges R., Schriewer A., Horn H. 2010. Runoff pollutants of a highly trafficked urban road - Correlation analysis and seasonal influences. Chemosphere, 80, 991-997.

14. Kelly M.G., Whitton B.A. 1995. The trophic diatom index: a new index for monitoring eutrophication in rivers. Journal of Applied Phycology, 7,433-444.

15. Kelly M.G. 1996. The trophic diatom index. Bowburn Consultancy, R\&D Technical Repot E2, 1-148.

16. Lewis M.A. 1986. Impact of Municipal Wastewater Effluent on Water Quality, Periphyton, and Invertebrates in the Little Miami River Near Xenia, Ohio. The Ohio Journal of Science, 86, 1, 2-8.

17. Ma Y., Gong M., Zhao H., Li X. 2018. Influence of low impact development construction on pollutant process of road-deposited sediments and associated heavy metals. Science of The Total Environment, 613-614, 1130-1139. doi: 10.1016/j. scitotenv.2017.09.174.

18. Madoni P. 1993. Ciliated protozoa and water quality in the Parma River (Northern Italy): long-term changes in the community structure. Hydrobiologia, 264. 129-135.

19. Madoni P., Zangrossi S. 2005. Ciliated protozoa and saprobical evaluation of water quality in the Taro River (northern Italy). Ital. J. Zool., 72, 21-25.

20. Oksanen J., Guillaume Blanchet F., Friendly M., Kindt R., Legendre P., McGlinn D., Minchin P. R., O’Hara R. B., Simpson G. L., Solymos P., Stevens M. H., Szoecs E. and Wagner H. 2019. vegan: Community Ecology Package. R package version 2.5-6. https://CRAN.R-project.org/package=vegan

21. Pliashechnyk V., Danko Y., Łagód G., Drewnowski J., Kuzmina T., Babko R. 2018. Ciliated protozoa in the impact zone of the Uzhgorod treatment plant. E3S Web of Conferences, 30 (02008), 1-7.

22. Poff N.L., Olden J.D., Merritt D.M., Pepin D.M. 2007. Homogenization of regional river dynamics by dams and global biodiversity implications. Proceedings of the National Academy of Sciences of the United States of America 104, 5732-5737.

23. Poff N.L., Zimmerman J.K.H. 2010. Ecological responses to altered flow regimes: A literature review to inform the science and management of environmental flows. Freshwater Biology, 55, 194-205. 
24. R Core Team, 2019. R: A language and environment for statistical computing. R Foundation for Statistical Computing, Vienna, Austria. https:// www.R-project.org/.

25. Schiefele S., Kohmann E., 1993. Bioindikation der Trophie in Fließgewässern. Bayerisches Landesamt für Wasserwirtschaft. Forschungsbericht $\mathrm{Nr}$. 10201504

26. Spänhoff B., Bischof R., Böhme A., Lorenz S., Neumeister K., Nöthlich A., Küsel K. 2007. Assessing the impact of effluents from a modern wastewater treatment plant on breakdown of coarse particulate organic matter and benthic macroinvertebrates in a lowland river. Water, Air, \& Soil Pollution, 180, 119-129.

27. Strom P. F., Matulewich V. A., Finstein M. S. 1976. Concentrations of nitrifying bacteria in sewages, effluents and a receiving stream and resistance of these organisms to chlorination. Appl. Environ. Microbiol., 31, 731-737.

28. Sun Z., Sokolova E., Brittain J.E., Saltveit S.J., Rauch S., Meland S. 2019. Impact of environmental factors on aquatic biodiversity in roadside stormwater ponds. Sci Rep., 9, 59-94. doi:10.1038/ s41598-019-42497-z.

29. Sweeney B.W., Bott T.L., Jackson J.K., Kaplan L.A., Newbold J.D., Standley L.J., Hession W.C., Horwitz R.J. 2004. Riparian deforestation, stream narrowing, and loss of stream ecosystem services. Proceedings of the National Academy of Sciences of the United States of America, 101, 14132-14137.

30. Vörösmarty C. J. et al. 2010. Global threats to human water security and river biodiversity. Nature, 467, 555-561.

31. Wakelin S.A., Colloff M.J., Kookana1 R.S. 2008. Effect of Wastewater Treatment Plant Effluent on Microbial Function and Community Structure in the Sediment of a Freshwater Stream with Variable Seasonal Flow. Appl Environ Microbiol., 74(9), 2659-2668.

32. Ward J.V., Tockner K., Schiemer F. 1999. Biodiversity of floodplain river ecosystems: Ecotones and connectivity. River Research and Applications, 15, 125-139.

33. Wickham H. 2009. ggplot2: elegant graphics for data analysis. Springer New York. 